\title{
PAULO OSÓRIO
}

\author{
Universidade da Beira Interior, Covilhã \\ paulosorio@hotmail.com
}

LISETE GASPAR

\section{OS VERBOS SER, ESTAR, TER E HAVER NO LEAL CONSELHEIRO DE D. DUARTE: ACHEGAS PARA UM QUADRO LINGUÍSTICO DO SÉCULO XV}

\begin{abstract}
Paulo Osório, Lisete Gaspar, Os verbos ser, estar, ter $e$ haver no "Leal Conselheiro" de D. Duarte: Achegas para um quadro linguístico do século $X V$ [Auxiliary verbs ser, estar, ter and haver in The Loyal Counsellor of Edward, King of Portugal. Towards a linguistic description of $15^{\text {th }}$ century Portuguese], Studia Romanica Posnaniensia, Adam Mickiewicz University Press, Poznań, vol. XL/1: 2013, pp. 115-134. ISBN 978-83-232-2542-3. ISSN 0137-2475. eISSN 2084-4158.
\end{abstract}

Being a text of profound personal introspection, the Leal Conselheiro was born to give voice to King Duarte's meditations on the real problems of human life and Portuguese people. His message was one of social projection and had a pedagogical purpose of national dimension, though it meant to cause an effect on the Portuguese moral and cultural identity that he wishes to see guided by timeless principles of Christian nature. Created in the Middles Ages, the book will also be a testimony of change and innovation in place, especially because this is a moment of linguistic transition and emancipation in which new and old forms need to coexist. In this essay we will be particularly focused on the verbs ser, estar, haver and ter, observing their semantics and syntactic proximity, achieving a study that involves the intrinsic relation between ser / estar and haver / ter. We'll analyse their evolution in order to explore common traces and meanings, but also the contexts that mark their individuality. Finally, we shall move towards the research provided by our corpus aiming at its quantitative and statistic treatment. We'll define the behavioural traces that involve the variables studied and we'll support the results on a specific group of syntactic and semantic criteria. Conclusively, according to the results, we'll point to the years between 1428 and 1430 to mark the birth of the manuscript. Placed on the beginning of the middle archaic period, the text reveals mostly cases of variation of forms, not necessarily the total consummation of change.

Keywords: historical linguistics; syntactic and semantic analysis of verbs SER, ESTAR, TER and HAVER; auxiliary verbs

A memória de Rosa Virgínia Mattos e Silva, a quem a Linguística Histórica muito deve...

\section{INTRODUÇÃO}

Reconstruir alguns fenómenos sintáctico-semânticos de uma fase pretérita da língua é um projecto tão ambicioso quanto desafiante. A fraca expressão dos estudos de ordem sintáctica é um facto que perturba o avanço da própria Linguística Histórica, 
mesmo sendo esta uma área que se encontra em plena expansão. É, pois, no século $\mathrm{XV}$, num momento de transição entre o português arcaico e o moderno, que situamos o nosso escopo de análise que será assente na análise linguística do percurso sintáctico-semântico de SER/ESTAR e TER/HAVER no Leal Conselheiro (LC) de D. Duarte. Quando escreveu o $L C$, D. Duarte não se preocupou com o esmero linguístico. Ele próprio afirma, no Prólogo, ter por intenção o entendimento das suas palavras, mais do que o exemplo literário. Todavia, reconhecemos nele uma formação aprimorada e acrescida das influências marcantes da época. Por este motivo, não é de todo absurdo encontrar no seu discurso algumas tendências que o afastem dos hábitos linguísticos do povo. Ainda assim, duvidamos que o seu comportamento linguístico se distancie sobremaneira da norma da restante comunidade, exceptuando no recurso aos latinismos tão em voga na época e no rigor ortográfico. Na verdade, o texto de D. Duarte reclama para si o privilégio da sua abundância textual, do seu enquadramento cronológico e do seu potencial linguístico, dentro de um envolvimento social riquíssimo e a transbordar prosperidade. Conta, ainda, com a vantagem de ser um único manuscrito de origem portuguesa e, portanto, livre das influências dos tradutores e das orientações particulares dos scriptoria.

\section{BREVE DESCRIÇÃO DO CORPUS}

Um dos grandes problemas do linguista histórico é reconstruir as fases pretéritas da língua com precisão. Na verdade, este trabalho só é possível pela análise da documentação escrita, mas esta encontra-se dispersa e, por vezes, fragmentada ou sujeita a cópias duvidosas, o que torna difícil a captação dos processos que estão na base da mudança linguística. Nem sempre é fácil reunir um corpus fiável e extrair dele mais do que suposições. É claro que, à medida que os estudiosos se vão aventurando e as investigações vão convergendo para resultados similares e coerentes, mais se desbrava o caminho e se esclarece o percurso dos tempos passados. Para esta finalidade, tem sido preferido o tratamento dos textos não-literários ao dos textos literários, uma vez que se aproximam muito mais das particularidades da linguagem oral. Aos textos literários fica reservada a dúvida acerca da sua fiabilidade ou da sua cronologia, pesando também o distanciamento em relação à linguagem oral. No entanto, tendo D. Duarte um objectivo educativo e não ficcional para o seu $L C$, e sendo este um texto em prosa, acreditamos tratar-se de um documento fiel ao padrão linguístico da época e extensível, na medida do possível, à comunidade portuguesa de quatrocentos. Temos de considerar aqui o distanciamento da sua formação comparativamente ao vulgo, pois esta não deixará de estar manifesta na escrita, ainda que de forma intencionalmente parcimoniosa.

Para a análise das variáveis sintácticas em questão, seleccionámos, então, um corpus exclusivamente composto pelo texto do $L C$. Da autoria do rei D. Duarte, este 
texto enquadra-se nos limites do ano de 1428-1438, portanto no século XV, e situa-se num momento histórico decisivo para Portugal, distinguido por uma nova abertura ao mundo. Este factor, só por si, vai privilegiar a nossa análise, na medida em que coloca a língua ao nível da própria emancipação social e, assim, previsivelmente susceptível a fenómenos de mudança linguística. Por outro lado, permitir-nos-á detectar alguns registos próprios da época e com eles validar outras investigações do mesmo teor. Reconhecemos que a inexistência de um confronto com outros textos produzidos pela corte ou representativos da mesma época e da mesma obra, não nos permite apurar certas particularidades diatópicas, diastráticas ou dialectais que sejam conclusivas; todavia, um foco mais concentrado apurará, certamente, aspectos determinantes do português quatrocentista.

A edição impressa que seleccionámos para a análise do $L C$ é a de Maria Helena Lopes de Castro, uma edição crítica, com introdução e notas da autora e prefácio de Afonso Botelho. Datada de 1999, esta edição foi feita através de fotografias do próprio manuscrito, depositado na BNP (ou BRP). A versão digitalizada que permitiu o levantamento das ocorrências e o estudo percentual dos dados é a que se insere no programa Phrasis (Projecto Vercial, versão 2.0, copyright (C) 2003 - 2007), que elegemos para essa mesma finalidade estatística, sendo que os dados levantados são decorrentes das limitações desta escolha. Trata-se de um programa de concordâncias de textos em português antigo (séculos XII - XVI). O texto do $L C$ é uma transcrição feita por José Barbosa Machado, a partir da edição de 1843 (Paris, Aillaud, publicada por José Inácio Roquete) e da edição de 1543 (Lisboa, Tipografia Rollandiana), em confronto com a edição de José Maria Piel (Lisboa, Bertrand, 1942) e a edição crítica de Maria Helena Lopes de Castro (Lisboa, Instituto Nacional Casa da Moeda, 1998).

\section{DO OBJETO AO MÉTODO DE ANÁLISE DAS VARIÁVEIS LINGUÍSTICAS DO CORPUS}

As variáveis que seleccionámos para conduzir o nosso trabalho são de argumentação sintáctica, mas com respeito pela sua interacção e dependência semântica. Propomo-nos observar, sincronicamente, os traços sintácticos dos verbos ser, estar, haver e ter e, com este objectivo, decidimos examinar um conjunto de traços específicos que definem o comportamento das variáveis em observação e do sistema verbal onde se inserem. Considerámos a sua distribuição na cadeia sintáctico-semântica, com vista a formar um padrão que favoreça a recolha, o agrupamento e o seu posterior tratamento.

Para proceder à nossa investigação, vamos socorrer-nos de alguns recursos técnicos e metodológicos, nomeadamente de enquadramentos teóricos que têm sido defendidos por Rosa Virgínia Mattos e Silva. De entre a variedade de métodos possíveis, 
escolhemos aquele que considerámos mais adequado aos nossos objectivos, sempre em consciência das limitações de qualquer opção. Optámos, assim, pelo método quantitativo, que prevê a mensuração das variáveis já pré-estabelecidas e permite analisar a frequência das incidências, bem como estabelecer relações entre as mesmas, com vista à descrição dos resultados. A aproximação quantitativa permite avaliar a vitalidade das formas, na medida em que demonstra a frequência do seu uso e, simultaneamente, a força que estas possuem dentro do sistema linguístico (e social) seu contemporâneo. Deste modo, sumariamos o nosso plano da seguinte forma:

- recolha e contagem estatística dos dados, numa perspectiva quantitativa da informação. Pelo recurso à versão digitalizada do $L C$, do Programa Phrasis, faremos a extracção e a contagem dos dados lexicais, para posteriormente serem expostos de forma estatística;

- análise dos dados e distribuição selectiva dos traços sintácticos em questão;

- distribuição axiológica dos dados e contagem estatística dos mesmos;

- interpretação linguística pelo recurso à argumentação sintáctica e semântica;

- amostragem percentual e gráfica dos resultados para uma apreciação comparativa.

A análise dos traços sintácticos dos verbos ser, estar, haver e ter exige uma preocupação com a descrição do carácter sintáctico e também semântico destes mesmos verbos, ou seja, com a sua natureza funcional dentro da estrutura frásica. E esta funcionalidade a que nos referimos centra-se no seu núcleo, ou seja, preocupa-se com as diversas possibilidades de expressar a predicação verbal, dentro da sua relação com o sujeito e com os complementos. Para tal, seguiremos de perto as considerações de Rosa Virgínia Mattos e Silva ${ }^{1}$ e tomaremos por base a classificação semânticosintáctica de predicados desenvolvida pela autora, bem como a análise da estrutura atributiva e do tipo de posse. Esta configura-se da seguinte forma:

a) predicados existenciais (ou impessoais), que se caracterizam por não seleccionarem sujeito e que no português arcaico se expressam pelos verbos haver e ser;

b) predicados atributivos subdivididos em quatro tipos:

- equativos (ou identificacionais), que se caracterizam semanticamente pela equivalência referencial entre o sujeito e o complemento do núcleo verbal do predicado. O verbo seer ocupava esta posição no período arcaico;

- descritivos, que se caracterizam semanticamente por atribuírem uma qualidade permanente ou transitória ao sujeito que se expressa por um nominal. Os verbos seer e estar ocupavam o núcleo do $\mathrm{SV}$, mas não lhes era exclusivo;

${ }^{1}$ Rosa Virgínia Mattos E Silva, O português arcaico. Uma aproximação. Vol. II - Sintaxe e morfologia, pp. 13-45; Rosa Virgínia Mattos E Silva, O português arcaico: fonologia, morfologia e sintaxe, pp. 147-159. 
- locativos, que se caracterizam semanticamente por apresentarem um complemento que localiza o sujeito de forma permanente ou transitória, no espaço, no tempo ou nocionalmente. Os verbos seer e estar representavam esta estrutura, a par com outros verbos;

- possessivos, que descrevem a relação de posse existente entre o possuidor e o (objeto) possuído. Por norma, têm como núcleo do SV o verbo (h)aver, que no período arcaico comutava com tẽẽr/teer.

c) predicados intransitivos, que requerem apenas o sujeito da frase. Todavia, dentro deste temos os verdadeiramente intransitivos, em que o sujeito não se assume como o agente do processo verbal, e os ergativos ou neutros, em que o sujeito não é nem origem nem agente;

d) predicados transitivos, que para além do sujeito, requerem pelo menos mais um argumento, seja SN ou SPREP.

Para além da definição do tipo de predicado, a nossa análise incorre, ainda, sob a discriminação semântica da estrutura atributiva. Orientada para a compreensão do sentido, valoriza a significação da estrutura frásica, no sentido de interpretar a intencionalidade discursiva. Este tipo de estrutura subdivide-se nos seguintes grupos: ADP - Atributiva Descritiva Permanente; ADT - Atributiva Descritiva Transitória; ALP - Atributiva Locativa Permanente; ALT - Atributiva Locativa Transitória; ALNP Atributiva Locativa Nocional Permanente; ALNT - Atributiva Locativa Nocional Transitória; ALG - Atributiva Locativa Geográfica.

Finalmente, sublinhamos, ainda, a análise da relação possessiva. Esta expressa uma dependência entre o sujeito e o predicado, relação essa que canaliza o valor semântico do objecto possuído. É da necessidade de distinguir no predicado diferentes indicadores de natureza semântica, que surge uma classificação que opera a três níveis: a) BMA - posse de bens materiais adquiríveis, exteriores ao possuidor; b) BIA - posse de bens/qualidades imateriais adquiríveis, intrínsecos ao possuidor; c) BI posse de bens inadquiríveis e inalienáveis, inerentes ao possuidor.

\section{ANÁLISE DO CORPUS}

Numa primeira apreciação dos dados documentais em análise, podemos observar a discrepância na totalidade das ocorrências recolhidas. Num total de 3948 registos, 2686 pertencem ao verbo ser. Naturalmente que mesmo sendo este o verbo que previsivelmente alcançaria maior projecção na estatística, não deixa de nos surpreender que este número concorra com apenas 781 ocorrências do verbo haver, 404 do verbo ter e 76 do verbo estar. Nitidamente em superioridade numérica, o verbo ser alcança uma percentagem que excede em larga escala os restantes dados desta amostragem. De acordo com os dados extraídos, e no que se refere à frequência de uso dos quatro verbos no corpus do $L C$, ser e haver dominam o universo destes verbos, o primeiro em $68 \%$ e o segundo em $20 \%$. Considerando o binómio serlestar, é inquestionável 
a preferência de ser sobre estar, que ocupa apenas $2 \%$ da amostragem. Do mesmo modo, também a observação do binómio haver / ter não deixa dúvidas quanto à superioridade de haver $(20 \%)$ relativamente a ter $(10 \%)$.

No que respeita à estrutura atributiva, considerámos tanto os atributos permanentes como os transitórios de carácter descritivo ou locativo. Verificamos, pois, que ser ocorre em todas as possibilidades, ainda que praticamente escasso em estruturas de tipo ALT/ALNT (locativo transitório, nocional ou não) ou em estruturas de tipo ALG (locativo geográfico). Predomina, indiscutivelmente, a descritiva permanente, com $92 \%$ conquistados do total de exemplos arrolados. O verbo estar, considerada a mesma estrutura, revela indicadores diferentes. A tabela que se segue indica a preferência para ocorrer em estruturas transitórias, sejam elas locativas ou descritivas:

Tabela 1

"Estar" em estrutura atributiva

\begin{tabular}{|c|l|c|}
\hline 1 & Atributiva Descritiva Permanente (ADP) & $10 \%$ \\
\hline 2 & Atributiva Descritiva Transitória (ADT) & $28 \%$ \\
\hline 3 & Atributiva Locativa Permanente (ALP) & $0 \%$ \\
\hline 4 & Atributiva Locativa Transitória (ALT) & $10 \%$ \\
\hline 5 & Atributiva Locativa Nocional Permanente (ALNP) & $24 \%$ \\
\hline 6 & Atributiva Locativa Nocional Transitória (ALNT) & $13 \%$ \\
\hline 7 & Atributiva Locativa Geográfica (ALG) & $15 \%$ \\
\hline \multicolumn{2}{|l|}{ Total } & $100 \%$ \\
\hline
\end{tabular}

Considerámos, também, a relação entre os verbos haver e ter dentro da análise atributiva. Relativamente a haver, verificámos, novamente, a primazia da estrutura descritiva sobre a locativa. Do mesmo modo, também os atributos permanentes superam os transitórios em larga escala. A este respeito, vejamos a tabela que se segue:

Tabela 2

"Haver" em estrutura atributiva

\begin{tabular}{|c|l|c|}
\hline 1 & Atributiva Descritiva Permanente (ADP) & $81 \%$ \\
\hline 2 & Atributiva Descritiva Transitória (ADT) & $16 \%$ \\
\hline 3 & Atributiva Locativa Permanente (ALP) & $1 \%$ \\
\hline 4 & Atributiva Locativa Transitória (ALT) & $0 \%$ \\
\hline 5 & Atributiva Locativa Nocional Permanente (ALNP) & $1 \%$ \\
\hline 6 & Atributiva Locativa Nocional Transitória (ALNT) & $1 \%$ \\
\hline 7 & Atributiva Locativa Geográfica (ALG) & $0 \%$ \\
\hline \multicolumn{2}{|l|}{ Total } & $100 \%$ \\
\hline
\end{tabular}


Em relação ao verbo ter, os resultados são semelhantes. É a estrutura descritiva a preferida, bem como o carácter permanente o mais seleccionado:

$\mathrm{Ca}$ os sobervosos muito sentem se outros com eles se querem igualar ou sobrepojalos, dos quaes eles se teem em maior conta. (Cap. LXXVI)

Os contextos locativos são os que apresentam uma frequência mais baixa, practicamente insignificante face aos restantes dados:

Pera esta val muito continuadamente querer saber toda cousa que razoada seja, guardando aquela palavra que, teendo na cova o pee, ainda desejamos daprender, per que se demostra como devemos sempre teer esta teençom; porque do boo aprender nace boo saber e jeito densinar. (Cap. I)

Veja-se a tabela seguinte para um melhor esclarecimento:

Tabela 3

"Ter" em estrutura atributiva

\begin{tabular}{|l|l|c|}
\hline 1 & Atributiva Descritiva Permanente (ADP) & $86 \%$ \\
\hline 2 & Atributiva Descritiva Transitória (ADT) & $11 \%$ \\
\hline 3 & Atributiva Locativa Permanente (ALP) & $1 \%$ \\
\hline 4 & Atributiva Locativa Transitória (ALT) & $1 \%$ \\
\hline 5 & Atributiva Locativa Nocional Permanente (ALNP) & $1 \%$ \\
\hline 6 & Atributiva Locativa Nocional Transitória (ALNT) & $0 \%$ \\
\hline 7 & Atributiva Locativa Geográfica (ALG) & $0 \%$ \\
\hline \multicolumn{2}{|l|}{ Total } & $100 \%$ \\
\hline
\end{tabular}

Igualmente importante para o nosso estudo é a observação do tipo de predicado como um indicador da expressão verbal face ao sujeito. Este foca as relações funcionais entre o SV - predicado, e o SN - sujeito, para a formação de frases, dentro de um contexto sintáctico-semântico. $\mathrm{O}$ conjunto de tabelas que se segue vai conduzir a conclusões interessantes a este respeito. Começemos por observar os dados referentes ao verbo ser:

"Ser" e o tipo de predicado

\begin{tabular}{|c|l|c|}
\hline 1 & Predicado Atributivo Descritivo (PAD) & $87 \%$ \\
\hline 2 & Predicado Atributivo Equativo (PAE) & $2 \%$ \\
\hline 3 & Predicado Atributivo Locativo (PAL) & $5 \%$ \\
\hline 4 & Predicado Atributivo Possessivo (PAP) & $0 \%$ \\
\hline 5 & Predicado Existencial (PE) & $4 \%$ \\
\hline 6 & Predicado Intransitivo (PI) & $2 \%$ \\
\hline \multicolumn{2}{|l|}{ Total } & $100 \%$ \\
\hline
\end{tabular}


O verbo estar demonstra um maior equilíbrio entre a estrutura predicativa locativa e a estrutura predicativa descritiva:

Outro ensinamento: cousa perigosa he scolher homem estar no lugar onde morrem de pestelença, e cousa mais segura partirse, ca mais morrem dos que ficam, e poucos dos que se partem. (Cap. LRV)

Mesmo sendo a locativa a que predomina, a variação entre elas é ainda muito próxima no contexto do $L C$. Este equilíbrio já se evidenciava nos contextos semânticos atributivos. Vejamos a tabela 5:

Tabela 5

"Estar" e o tipo de predicado

\begin{tabular}{|c|l|c|}
\hline 1 & Predicado Atributivo Descritivo (PAD) & $39 \%$ \\
\hline 2 & Predicado Atributivo Equativo (PAE) & $0 \%$ \\
\hline 3 & Predicado Atributivo Locativo (PAL) & $57 \%$ \\
\hline 4 & Predicado Atributivo Possessivo (PAP) & $0 \%$ \\
\hline 5 & Predicado Existencial (PE) & $4 \%$ \\
\hline 6 & Predicado Intransitivo (PI) & $0 \%$ \\
\hline \multicolumn{2}{|l|}{ Total } & $100 \%$ \\
\hline
\end{tabular}

O verbo haver evidencia-se pela predominância do predicado de tipo possessivo $(52 \%)$, variando nesta estrutura com o verbo ter:

Per aquesta repartiçom, vos poderees haver algüu special conhecimento de nossos falicimentos. (Cap. LXVII)

Todavia, a posse não é exclusiva a este verbo, e se observarmos o gráfico atentamente, verificamos um alto número de ocorrências para os atributivos descritivos e algumas dentro da estrutura existencial. Os resultados do PAD devem-se, em parte, à flutuação semântica entre haver, ser e ter, onde estes surgem em sinonímia. Vejamos a tabela correspondente:

"Haver" e o tipo de predicado

\begin{tabular}{|c|l|c|}
\hline 1 & Predicado Atributivo Descritivo (PAD) & $31 \%$ \\
\hline 2 & Predicado Atributivo Equativo (PAE) & $0 \%$ \\
\hline 3 & Predicado Atributivo Locativo (PAL) & $2 \%$ \\
\hline 4 & Predicado Atributivo Possessivo (PAP) & $52 \%$ \\
\hline 5 & Predicado Existencial (PE) & $12 \%$ \\
\hline 6 & Predicado Intransitivo (PI) & $3 \%$ \\
\hline \multicolumn{2}{|l|}{ Total } & $100 \%$ \\
\hline
\end{tabular}


O verbo ter, como previsível, é escolhido para a expressão da posse em $63 \%$ dos exemplos existentes. Também se verificam alguns resultados para a estrutura PAD, à semelhança do verbo haver, mas é bem clara a predominância dos atributos possessivos sobre os descritivos. No período arcaico, haver e ter não estavam em variação livre nas estruturas de posse. É só na passagem do século XIV para o século XV que o verbo ter dá sinais de superar haver e de afirmar-se como principal verbo para designar a posse, ainda que possam comutar em determinados contextos. Vejamos quais os principais atributos que aparecem com haver e com ter:

"Haver" e o tipo de posse

\begin{tabular}{|c|l|c|}
\hline 1 & Bens Materiais Adquiríveis (BMA) & $41 \%$ \\
\hline 2 & Bens Imateriais Adquiríveis (BIA) & $37 \%$ \\
\hline 3 & Bens Inerentes (BI) & $22 \%$ \\
\hline \multicolumn{2}{|l|}{ Total } & $100 \%$ \\
\hline
\end{tabular}

Tabela 8

"Ter" e o tipo de posse

\begin{tabular}{|c|l|c|}
\hline 1 & Bens Materiais Adquiríveis (BMA) & $29 \%$ \\
\hline 2 & Bens Imateriais Adquiríveis (BIA) & $57 \%$ \\
\hline 3 & Bens Inerentes (BI) & $14 \%$ \\
\hline \multicolumn{2}{|l|}{ Total } & $100 \%$ \\
\hline
\end{tabular}

Os atributos de tipo BMA e BIA ocorrem de forma equilibrada com o verbo haver, sendo inferior a frequência da estrutura de tipo BI. Com o verbo ter aparece a posse de tipo BI em último lugar e a de tipo BIA em primeiro, esta relativamente distante da de tipo BMA. Ora, isto não acontece com haver, em que a proximidade entre ambas destaca subtilmente o tipo de posse BMA comparativamente a BIA. Com estes dados é-nos apenas possível confirmar que ter supera haver no tipo de posse BIA, mas haver supera ter nas de tipo BMA. A posse de tipo BI é ainda superior com o verbo haver. Assim, confirmamos que a expansão de ter sobre o campo semântico de haver se difunde primeiro do contexto BIA para o BMA.

No conjunto das possibilidades de ocorrência dos verbos em questão, foram levantadas as referentes às estruturas em que ser, estar, haver e ter ocorrem com particípio passado, gerúndio e infinitivo 2 . Para o efeito, considerámos apenas as construções

${ }^{2}$ Sobre a caracterização das perífrases com infinitivo, gerúndio e particípio, Emílio Alarcos procura fazer uma distinção de carácter geral e simplificado, que vai de encontro às várias teorias encabeçadas por outros estudiosos sobre esta matéria e que se apresenta nos seguintes moldes: «[...] las perífrasis con infinitivo ofrecen una perspectiva de realización, un valor progresivo, un valor 
plenas, em que as formas verbais em questão representam o auxiliar da forma verbal composta. Advertimos que o resultado obtido é, no entanto, limitado para uma descrição mais ampla do problema, pois o número de casos encontrados é bastante diminuto (com excepção do verbo ser que possui um número de exemplos mais significativo). Ainda assim, podemos adiantar algumas conclusões e corroborar com outros estudos a respeito. Desta forma, aceitamos a limitação que o corpus nos impõe e avançamos, com segurança, para a exploração das tabelas que se seguem:

Tabela 9

"Ser" nas diferentes modalidades nominais

\begin{tabular}{|r|l|r|}
\hline 1 & Ser + Particípio Passado & 1112 ocs. \\
\hline 2 & Ser + Gerúndio & 3 ocs. \\
\hline 3 & Ser + Infinitivo & 27 ocs. \\
\hline
\end{tabular}

De acordo com a tabela, o verbo ser ocorre em número superior quando acompanhado de Particípio Passado (98\%), sendo quase insignificante o número de ocorrências registadas para as restantes modalidades ( $2 \%$ com Infinitivo e $0 \%$ com Gerúndio). É aqui importante referir que a aceitação do Particípio Passado como um tempo composto permanece envolvida em alguma controvérsia. Autores como Said $\mathrm{Ali}^{3}$ e Mattoso Câmara $\mathrm{Jr}^{4}{ }^{4}$ insistem que quando a flexão do particípio concorda com o objecto directo, não se pode considerar um tempo composto, pois não se dá a fusão sintáctico-semântica implícita nesse tipo de construção verbal. Por outro lado, também é fraca a unanimidade quanto à definição do momento da história da língua em que este fenómeno terá sofrido mudanças e a partir de que momento podemos realmente falar de tempos compostos.

Desta forma, advertidos para esta directiva, tivemos especial atenção à nossa recolha, por forma a detectar as construções que pudessem levantar alguma controvérsia e que, na verdade, não formassem um tempo composto verdadeiro, mas duas acções simultâneas que pudessem confundir-se numa só. Oportunamente, são nulos, no nosso corpus, os registos deste particípio a concordar com o objecto directo. Na verdade, os poucos exemplos irregulares que encontrámos podem ser apenas um erro, tanto de impressão, como do copista, uma vez que não formam um padrão minimamente sugestivo. Desta forma, é pouco provável que existisse variação na concordância do particípio passado.

futuro, las perífrasis con gerundio un carácter continuativo, durativo y las perífrasis con participio un valor retrospectivo, perfectivo, dirigido hacia el pasado». Emilio Alarcos Llorach, Estúdios de gramática funcional del español. Madrid, Gredos, 1970, pp. 57-60.

${ }^{3}$ Said Ali, M., Dificuldades da língua portuguesa. Rio de Janeiro, Livraria Académica, 1957, p. 126.

4 Mattoso Câmara Jr., Uma forma verbal portuguesa. Rio de Janeiro, Livraria Académica, 1956, p. 82. 
Continuando a explorar a ocorrência das diferentes modalidades nominais com as formas verbais em questão, vamos agora passar para o verbo estar e tirar as conclusões que os dados nos permitem relativamente a este verbo. Vejamos, então, a tabela:

"Estar" nas diferentes modalidades nominais

\begin{tabular}{|c|l|c|}
\hline 1 & Estar + Particípio Passado & 9 ocs. \\
\hline 2 & Estar + Gerúndio & 1 ocs. \\
\hline 3 & Estar + Infinitivo & 0 ocs. \\
\hline
\end{tabular}

Com o verbo estar, a modalidade predominante é também a do Particípio Passado, com $90 \%$. A esta segue-se o Gerúndio, com $10 \%$, e o Infinitivo sem nenhuma ocorrência:

"Haver" nas diferentes modalidades nominais

Tabela 11

\begin{tabular}{|c|l|c|}
\hline 1 & Haver + Particípio Passado & 14 ocs. \\
\hline 2 & Haver + Gerúndio & 0 ocs. \\
\hline 3 & Haver + Infinitivo & 131 ocs. \\
\hline
\end{tabular}

O verbo haver mostra um resultado distinto dos anteriores, com um destaque de $90 \%$ para a estrutura com Infinitivo. Seguem-se os $10 \%$ de frequência para o Particípio Passado e nenhuma ocorrência para o Gerúndio:

“Ter" nas diferentes modalidades nominais

\begin{tabular}{|c|l|c|}
\hline 1 & Ter + Particípio Passado & 35 ocs. \\
\hline 2 & Ter + Gerúndio & 0 ocs. \\
\hline 3 & Ter + Infinitivo & 5 ocs. \\
\hline
\end{tabular}

Com o verbo haver, destacam-se as estruturas com Particípio Passado (87\%), seguindo-se o Infinitivo (13\%) e o Gerúndio sem qualquer ocorrência. Podemos, assim, concluir que o Particípio Passado ocorre predominantemente com os verbos ser, estar e ter e que com os mesmos são quase inexistentes as ocorrências com o Gerúndio e com o Infinitivo. É o verbo ser que apresenta mais exemplos com Particípio, seguindo-se ter, haver e estar, nesta ordem. Este é um dado muito interessante, na medida em que ter supera haver neste tipo de construção, o que comprova a sua expansão e a sua afirmação como seu sucessor. Apesar de partirmos de um corpus muito 
específico e, portanto, parcialmente representativo do estado da língua no século XV, os resultados são exactos e muito significativos. Note-se que esta tendência é análoga à das estruturas possessivas, em que também ter é o verbo mais seleccionado. Esta é, pois, uma fase privilegiada na história da língua portuguesa, onde podemos percepcionar as mudanças que traçarão, mais tarde, as linhas do português moderno.

Igualmente importante é observar o comportamento sintáctico destas estruturas. A par com a predominância das ocorrências, verificámos também a existência de seis tipos distintos de formação com o Particípio Passado. As tabelas que se seguem exemplificam as tendências dos dados do corpus. Assim sendo, vamos examinar cada uma delas, individualmente:

Tipo 1: (aux. + part. passado + G.N.)

\begin{tabular}{|l|l|l|l|}
\hline Ser & Ter & Haver & Estar \\
\hline 273 ocs. & 9 ocs. & 4 ocs. & 3 ocs. \\
\hline
\end{tabular}

Tipo 2: (G.N. + aux. + part. passado)

\begin{tabular}{|l|l|l|l|}
\hline Ser & Ter & Haver & Estar \\
\hline 258 ocs. & 22 ocs. & 7 ocs. & 1 ocs. \\
\hline
\end{tabular}

Tipo 3: (G.N. + part. passado + aux.)

\begin{tabular}{|l|l|l|l|}
\hline Ser & Ter & Haver & Estar \\
\hline 29 ocs. & 1 oc. & 0 ocs. & 0 ocs. \\
\hline
\end{tabular}

Tipo 4: (part. passado + aux. + G.N.)

\begin{tabular}{|l|l|l|l|}
\hline Ser & Ter & Haver & Estar \\
\hline 17 ocs. & 0 ocs. & 0 ocs. & 0 ocs. \\
\hline
\end{tabular}

Tipo 5: (aux. + G.N. + part. passado)

\begin{tabular}{|l|l|l|l|}
\hline Ser & Estar & Haver & Ter \\
\hline 159 ocs. & 4 ocs. & 3 ocs. & 3 ocs. \\
\hline
\end{tabular}

Tipo 6: (part. passado + G.N. + aux.)

\begin{tabular}{|l|l|l|l|}
\hline Ser & Estar & Haver & Ter \\
\hline 2 ocs. & 0 ocs. & 0 ocs. & 0 ocs. \\
\hline
\end{tabular}

As estruturas predominantes são, portanto, as de tipo 1 e 2, com um grau de frequência muito próximo um do outro. Entre ser e estar, a preferência recai sobre o primeiro, que também oferece um corpus de análise muito mais extenso. Entre haver e ter, a primazia é de ter em todos os tipos registados. Ora, esta superioridade 
assevera a sua expansão em relação a haver e, mais uma vez, é um claro indício de que ter se encontrava no caminho certo para se tornar o verbo mais seleccionado na representação deste tipo de locução verbal. Por outro lado, observámos anteriormente que a estrutura do tempo composto só seria legítima a partir do momento em que este deixasse de ser flexionado em concordância com o complemento. Ora, as conclusões a que chegámos é que essa concordância não se verifica, pelo que não podemos falar de variação, mas sim de unificação. É, pois, esta uma fase de inovação da língua, claramente sugerida e reflectida no trabalho de D. Duarte, e já dominante num corpus com esta extensão. Reconhecemos que não aspiramos a mais do que uma pequena sondagem. No entanto, a ausência de flutuação neste tipo de construção é deveras marcante e não deve ser tratada como uma mera curiosidade. Acreditamos que o facto de se tratar de uma obra de Avis, tenha grande influência nos resultados, não fosse este o punho que deu à língua portuguesa a expressão da modernidade. Será que podemos afirmar que, neste momento, estava em marcha o português arcaico médio?

Por oposição, o verbo haver inverte os papéis e dá primazia às estruturas com Infinitivo, para relegar para segundo lugar o Particípio Passado e o Gerúndio. Nas perífrases formadas com Infinitivo, confirma-se, pois, que é haver o verbo mais seleccionado neste corpus do século XV:

\begin{tabular}{|l|l|l|l|}
\hline Haver & Ter & Ser & Estar \\
\hline $90 \%$ & $13 \%$ & $4 \%$ & $0 \%$ \\
\hline
\end{tabular}

Confirmada a preferência pela perífrase formada com haver, retomamos a observação destas ocorrências perifrásticas lembrando que, à semelhança do que aconteceu com as estruturas formadas com Particípio, continua a não existir uma estrutura fixa para a sua formação, pois no corpus pudemos encontrar três tipos distintos, todos eles prováveis com ser, haver e ter. Vejamos os exemplos e a frequência das ocorrências:

Tipo 1: (Ser/Haver/Ter (de) + inf.)

\begin{tabular}{|l|l|l|}
\hline Ser & Haver & Ter \\
\hline 27 ocs. & 120 ocs. & 5 ocs. \\
(2 sem a preposição "de") & $(5$ sem a preposição “de”) & com a preposição "de") \\
\hline
\end{tabular}

Tipo 2: (Ser/Haver/Ter + _ + (de) + inf. $)$

\begin{tabular}{|l|l|l|}
\hline Haver & Ser & Ter \\
\hline $\begin{array}{l}9 \text { ocs. } \\
\text { ( com a preposição "de") }\end{array}$ & 0 ocs. & 0 ocs. \\
\hline
\end{tabular}


Tipo 3: (Ser/Haver/Ter de + + inf.)

\begin{tabular}{|l|l|l|}
\hline Haver & Ser & Ter \\
\hline 2 ocs. & 0 ocs. & 0 ocs. \\
\hline
\end{tabular}

Em suma, regista-se a preferência pela perifrástica de tipo 1, na qual os elementos se apresentam contíguos. Esta pode surgir com ou sem a preposição "de", tendo maior vigor o uso da preposição, mas não havendo qualquer registo que evidencie a escolha pela preposição "a". A nível semântico, verifica-se a mesma intencionalidade na escolha da perífrase com haver, muitas vezes marcada pela futuridade, e também no valor de obrigatoriedade ou necessidade infligido pela perífrase com ter. $\mathrm{O}$ verbo ser reforça significativamente a oração existencial, embora mostre indícios de necessidade e de futuridade. Curiosamente, os verbos ser e ter não manifestam os tipos 2 e 3, mas o verbo haver espraia-se pelos 3 tipos definidos, valorizando a sua presença na perifrástica de tipol. Apenas os verbos ser e estar ocorrem no corpus seguidos de Gerúndio. O verbo estar apresenta apenas um caso. Tanto ser como estar funcionam como auxiliares dos verbos acustumar, ajuntar, tocar e pensar, formando com eles uma estrutura perifrástica legítima. Nenhum deles se assume na sua significação plena, portanto, todos se libertam do seu significado lexical para dar uma nova vitalidade aos verbos principais a que se associam. Em todos os casos, a acção expressa um acto único, durativo ou continuado. Formam, portanto, uma locução verbal ou tempo composto.

\section{CONLUSÃO}

Tratando-se de um corpus único $(L C)$ e que, por isso, não torna possível podermos observar momentos precisos no processo de mudança dos fenómenos em análise, a nossa investigação permite reconhecer a coexistência entre variantes antigas e modernas e, em alguns casos, antever aquela que seria seleccionada para prevalecer no futuro. Por outro lado, é igualmente importante frisar que o $L C$ apresenta já uma combinação sintáctico-semântica extremamente coerente. Relacionando as características que definem o período arcaico médio com os dados do nosso estudo, as conclusões que apurámos apontam para a localização do $L C$ no início deste período, uma vez que encontramos, maioritariamente, formas em variação e não mudanças totalmente consumadas. A ser assim, não poderemos situar a obra num momento amadurecido do português arcaico médio, mas numa fase inicial e de transição. Assim, arriscamos sugerir que o $L C$ terá sido redigido nos primeiros anos do casamento de D. Duarte, entre 1428 e 1430, talvez, não ultrapassando um limite razoável para a fase mais jovem deste período da língua.

Podemos concluir que ser e haver estão em vantagem numérica no quadro geral da amostra, ainda que ser domine este universo com larga superioridade. Conside- 
rando o binómio ser / estar, é clara a preferência por ser, já que estar ocupa apenas $2 \%$ da amostragem. Relativamente ao binómio haver / ter, a preferência recai sobre haver, com o dobro de ocorrências. A observação da distribuição das ocorrências por unidades modo-temporais aponta para diferentes ilações, destacando-se a preferência pelo uso do tempo Presente e do modo Indicativo. Esta preferência justifica-se pela natureza literária e semântica do próprio texto. Na expressão do presente, D. Duarte faz a análise social, ética e moral que domina as linhas do $L C$ e que está em conformidade com o seu tempo e com o contexto a si contemporâneo. $\mathrm{O}$ tom das premissas alcança intemporalidade pela adopção de um registo realista e objectivo, que reforça os valores que enunciam os factos textuais e que preconiza uma actuação predominantemente pedagógica e finalística.

Com ser predomina fortemente a estrutura atributiva descritiva de carácter permanente. Com estar predomina a estrutura de tipo transitório, seja locativa ou descritiva. Este verbo distribui-se com maior equilíbrio pelas diferentes estruturas. Com haver verifica-se a primazia da estrutura descritiva sobre a locativa e dos contextos permanentes sobre os transitórios. Com ter predomina a descritiva e o carácter permanente, à semelhança do verbo haver. Em relação ao binómio ser / estar, podemos estabelecer um quadro comparativo dentro da estrutura atributiva, de modo a verificar quais os tipos que revelam maior frequência e quais possam registar índices mais baixos de concentração:

"Ser" e "Estar" em estrutura atributiva

\begin{tabular}{|l|c|c|c|c|c|c|c|} 
& ADP & ADT & ALP & ALT & ALNP & ALNT & ALG \\
\hline Ser & $92 \%$ & $4 \%$ & $2 \%$ & $0 \%$ & $2 \%$ & $0 \%$ & $0 \%$ \\
\hline Estar & $10 \%$ & $28 \%$ & $0 \%$ & $10 \%$ & $24 \%$ & $13 \%$ & $15 \%$ \\
\hline
\end{tabular}

Legenda: ADP - Atributiva Descritiva Permanente; ADT - Atributiva Descritiva Transitória; ALP - Atributiva Locativa Permanente; ALT - Atributiva Locativa Transitória; ALNP - Atributiva Locativa Nocional Permanente; ALNT - Atributiva Locativa Nocional Transitória; ALG - Atributiva Locativa Geográfica.

Do conjunto dos dados, verificamos que as estruturas atributivas descritivas ocorrem com maior frequência em ser do que em estar. Já as locativas são superiores com estar, face à ocorrência quase nula com ser. Do mesmo modo, regista-se a preferência de ser em estruturas semanticamente permanentes e de estar em estruturas semanticamente transitórias. Confirma-se, igualmente, que o avanço de estar sobre ser, em contextos semanticamente transitórios, cresce mais nas estruturas locativas do que nas descritivas.

Com estes dados, concluímos e corroboramos significativamente com estudos anteriores, na asserção de que, no século $\mathrm{XV}$, o verbo ser era claramente preferido em estruturas descritivas e permanentes, substituindo estar dentro desta variação semântica, enquanto que o verbo estar era, sem dúvida, o verbo típico para a expressão dos atributos locativos e descritivos transitórios. 
A observação do binómio haver / ter dentro da estrutura atributiva revela indicadores interessantes, pelo que também elaborámos um quadro de leitura comparativa. Vejamos os dados expostos:

"Haver" e "Ter" em estrutura atributiva

\begin{tabular}{|l|c|c|c|c|c|c|c|}
\hline & ADP & ADT & ALP & ALT & ALNP & ALNT & ALG \\
\hline Haver & $80 \%$ & $16 \%$ & $1 \%$ & $0 \%$ & $2 \%$ & $1 \%$ & $0 \%$ \\
\hline Ter & $85 \%$ & $11 \%$ & $1 \%$ & $1 \%$ & $1 \%$ & $1 \%$ & $0 \%$ \\
\hline
\end{tabular}

Legenda: ADP - Atributiva Descritiva Permanente; ADT - Atributiva Descritiva Transitória; ALP - Atributiva Locativa Permanente; ALT - Atributiva Locativa Transitória; ALNP - Atributiva Locativa Nocional Permanente; ALNT - Atributiva Locativa Nocional Transitória; ALG - Atributiva Locativa Geográfica.

Pela leitura dos dados, verificamos que as estruturas atributivas descritivas ocorrem de forma muito equilibrada com haver e com ter e o mesmo acontece com as locativas, cuja percentagem de ocorrências é, também, muito próxima. Do mesmo modo, idêntico equilíbrio se verifica na preferência de ambos os verbos por estruturas semanticamente permanentes. Entre os contextos transitórios há, igualmente, um nível de ocorrência equilibrado. Com estes dados, somos obrigados a concluir que haver e ter coexistiam nos mesmos contextos semânticos e predominavam em contextos atributivos descritivos permanentes.

Com ser predominam largamente os predicados atributivos descritivos. Uma leitura comparativa destes dados relativamente aos da estrutura atributiva revela coerência de resultados, pois este já era o verbo predominante para os contextos descritivos (permanentes, no caso). Com estar dominam os predicados locativos e não há qualquer representação para os de tipo PAE, PAP e PI. Os descritivos também têm uma representação significativa. Com haver predominam os predicados possessivos, com representação significativa para os de tipo descritivo e existencial. Não se representam os de tipo PAE. Com ter também predominam os possessivos, como seria de prever, com alguma representação dos de tipo descritivo. Não há ocorrências para os tipos PAE.

É, igualmente, importante destacar a preferência de haver como verbo existencial, comparativamente a ter, cuja ocorrência é quase inexistente, mas não a ser, cuja percentagem de ocorrências aparenta valores consideravelmente inferiores, mas apenas enquanto valor percentual, pois é ocasionado em função da relação entre o conjunto dos restantes tipos de predicado, do mesmo modo que se protagoniza num universo de ocorrências totalmente distinto. Se compararmos exclusivamente o número de ocorrências, percebemos que a proximidade é muito grande, com 100 ocorrências para o verbo ser e 99 para o verbo haver. Deste modo, apesar de vários estudos apurarem a emancipação de haver neste tipo de estrutura, já no século XV, a proximidade deste com ser não nos oferece as mesmas conclusões, apenas nos permitindo confirmar que ainda se encontravam em variação livre. 
Com haver predominam os tipos BMA, evoluindo para os tipos BIA e BI. Com ter predominam os tipos BIA, seguindo-se os tipos BMA e BI. As estruturas de posse evoluem de forma diferente com cada verbo. ter supera haver nos tipos BIA e haver supera ter nos tipos BMA. A posse de tipo BI é de menor frequência em ambos, ainda que ligeiramente superior com haver. Assim, confirmamos que a expansão de ter sobre o campo semântico de haver se difunde primeiro do contexto BIA para o BMA. Todavia, é importante referir que a explicação para esta conclusão pode residir na natureza semântica do próprio texto, como abordámos anteriormente, na medida em que esta pode exercer uma grande influência em alguns resultados, justamente por se tratar de um texto ético-moral, em que abundam os indicadores espirituais acima dos materiais. Este apontamento pode, por si só, justificar a maior ocorrência de uma estrutura sobre a outra, e não servir de marco linguístico típico do século XV.

Com ser predominam exemplos com o Particípio Passado, existindo uma fraquíssima representação das estruturas com Gerúndio. Com estar a modalidade predominante é, também, o Particípio Passado, não existindo estruturas com o Infinitivo. Com haver predominam as estruturas com Infinitivo, não se fazendo representar com o Gerúndio. Com ter também predominam as estruturas com Particípio Passado e não se representa com o Gerúndio.

Concluímos que é o Particípio Passado a modalidade nominal que mais se representa com os verbos ser, estar e ter. As ocorrências com ter+part. passado superam as de haver em número, o que aponta para a sua expansão enquanto seu sucessor. Dentro deste quadro, são ainda as estruturas de tipo 1 (aux.+part. Passado + G.N.) e 2 (G.N. + aux. + part.passado) que apresentam maior frequência de ocorrências. Nestas, ser supera estar e ter supera haver. Predominam também as perífrases de tipo 1 (aux. (de) + inf.). Com haver há ocorrências com todos os tipos, o que não se verifica com os restantes auxiliares.

O Gerúndio tem uma representação muito reduzida e apenas com ser e estar.

Destaca-se o verbo "dever" como auxiliar predominante com todos os verbos. Este facto decorre da natureza textual do $L C$, fortemente imbuída de um discurso moralista e cristão.

\section{BIBLIOGRAFIA}

Alarcos Llorach, Emilio (1970): Estúdios de gramática funcional del español. Madrid: Gredos. Alonso-Cortés, Ángel (2000): Lingüistica. Madrid: Edições Cátedra.

ARrudA, Lígia Maria de Melo (1987): Contribuição para o estudo das nominalizações com o verbo suporte TER. Lisboa: Universidade de Lisboa.

BAPTISTA, Jorge (2005): Sintaxe dos predicados nominais com "Ser de". Lisboa: Fundação Calouste Gulbenkian.

Barbosa, João Morais (1982): Dom Duarte - Leal Conselheiro. (Actualização ortográfica, introdução e notas de). Lisboa: Imprensa Nacional Casa da Moeda (Biblioteca de Autores Portugueses). 
Bosque, Ignacio (1998): Las categorías gramaticales. Relaciones y diferencias. Madrid: Editorial Sintesis.

Bynon, Theodora (1977): Lingüistica histórica. Madrid: Biblioteca Románica Hispánica, Editorial Gredos, S.A., Cambridge University Press (versión española de José L. Malena).

CÂMARA JR., Joaquim Mattoso (1956): Uma forma verbal portuguêsa. Estudo estilístico-gramatical. Rio de Janeiro: Livraria Acadêmica.

CARDEIRA, Esperança (2005): Entre o português antigo e o português clássico. Lisboa: Imprensa Nacional Casa da Moeda.

CARDEIRA, Esperança (2009): «Revisitando a periodização do português: o português médio». Domínios de Lingu@gem 3 (2-2): 103-115.

CARdeira, Esperança; Fernandes, Maria Alice (2008): «O português medieval: koinização e elaboração». Veredas (Revista da Associação Internacional de Lusitanistas) 9: 155-176.

CAstro, Ivo (1993): «A elaboração da língua portuguesa, no tempo do infante D. Pedro». Biblos. Revista da Faculdade de Letras LXIX (Número especial com as Actas do Congresso Comemorativo do $6 .^{\circ}$ Centenário do Infante D. Pedro, 25 a 27 de Novembro de 1992): 97-106.

CASTro, Ivo (2006): Introdução à história do português. 2. ${ }^{a}$ ed. Lisboa: Edições Colibri.

CAstro, Maria Helena Lopes de (1995): «“Leal Conselheiro”. Itinerário do manuscrito». Penélope: revista de histôria e ciências sociais 16: 109-124.

Castro, Maria Helena Lopes de (1996): Dom Duarte. Leal Conselheiro (Colecção Pensamento Português). Lisboa: Imprensa Nacional Casa da Moeda.

Emiliano, António (2003): O tratamento dos dados da linguística histórica e da história da língua: fixação, disponibilização, análise e interpretação de fontes primárias medievais (considerações gerais sobre métodos e procedimentos). Lisboa: Universidade Nova de Lisboa - Faculdade de Ciências Sociais e Humanas.

FERREIRA, João Rodrigues (1994): Contributos para o estudo da evolução dos verbos ter $e$ haver na lingua portuguesa. Braga: Universidade do Minho.

Ferreira, José de Azevedo (1980/81): «Les verbes haber - tener et l'emploi de l'anaphorique y dans le "Libro de los Gatos"». Boletim de Filologia XXVI: 245-270.

Leal Conselheiro e Livro de ensinança de bem cavalgar toda sella (1843). Lisboa: Typographia Rollandiana.

LoBo, Tânia (1992): A colocação dos clíticos em português. Duas sincronias em confronto. Lisboa: Faculdade de Letras da Universidade de Lisboa.

LoRENZo, Ramón (1988): «Consideracións sobre as vocais nasais e o ditongo -ão en português». In Dieter Kremer [ed.]. Homenagem a Joseph M. Piel por ocasião do seu $85^{\circ}$ aniversário. Tübingen: Max Niemeyer Verlag, 289-326.

MAIA, Clarinda de Azevedo (1995): «Sociolinguística histórica e periodização linguística. Algumas reflexões sobre a distinção entre "português arcaico" e "português moderno"». Diacrítica 10: $5-11$.

MAIA, Clarinda de Azevedo (1999): «Periodização na história da língua portuguesa: status quaestionis e perspectivas de investigação futura». In: Eberhard GärTnER, Cristine HundT, Axel ScHÖNBERGER [eds.]. Estudos de história da língua portuguesa. Frankfurt am Main: TFM (Biblioteca luso-brasileira), 21-39.

MAIA, Clarinda de Azevedo (2002): «Dos textos escritos à história da língua». In: Brian F. HEAD, José Teixeira, Aida Sampaio Lemos, Anabela Leal de Barros, António Perreira [eds.]. História da língua e história da gramática: Actas do encontro [Braga, 16-18 de Novembro de 2000]. Braga (Centro de Estudos Humanísticos): Universidade do Minho, 231-249.

Martins, Ana Maria (2002): «Mudança sintáctica e história da língua portuguesa». In: Brian F. Head, José Teixeira, Aida Sampaio Lemos, Anabela Leal de Barros, António Perreira [eds.]. 
História da língua e história da gramática: Actas do encontro [Braga, 16-18 de Novembro de 2000]. Braga (Centro de Estudos Humanísticos): Universidade do Minho, 251-297.

Mattos E SiLva, Rosa Virgínia (1973): «O estudo linguístico de um texto português do século XIV». Boletim de Filologia XXII: 264-280.

Mattos E Silva, Rosa Virgínia (1980/1981): «Sobre a mudança linguística: uma revisão histórica». Boletim de Filologia XXVI: 83-99.

Mattos E Silva, Rosa Virgínia (1986): Contribuição para a leitura crítica de textos medievais portugueses: sintaxe e grafia. Paris: Fondation Calouste Gulbenkian - Centre Culturel Portugais.

Mattos E Silva, Rosa Virgínia (1988): «Diversidade e unidade: a aventura linguística do português». Revista ICALP 11:60-72 e Revista ICALP 12/13: 13-28.

Mattos E Silva, Rosa Virgínia (1989): Estruturas trecentistas. Elementos para uma gramática do português arcaico (Estudos Gerais - série universitária). Lisboa: Imprensa Nacional Casa da Moeda.

Mattos E SiLVA, Rosa Virgínia (1997): «Observações sobre a variação no uso dos verbos "ser", "estar", "haver", "ter" no galego-português ducentista». Estudos lingüísticos e literários 19: 253-286.

Mattos E SiLva, Rosa Virgínia (2006): O português arcaico: fonologia, morfologia e Sintaxe. São Paulo: Editora Contexto.

Mattos E Silva, Rosa Virgínia (2008): O português arcaico. Uma aproximação. Vol. II - Sintaxe e morfologia. Lisboa: Imprensa Nacional Casa da Moeda.

Osório, Paulo (2004): Contributos para uma caracterização sintáctico-semântica do português arcaico médio. Covilhã: Universidade da Beira Interior Editora.

SaID Ali, Manuel (1957): Dificuldades da língua portuguêsa. Estudos e observações (5. a ed.). Rio de Janeiro: Livraria Acadêmica.

SAID Ali, Manuel (1966): Gramática histórica da língua portuguesa. São Paulo: Edições Melhoramentos.

SiLVA, Jaime Ferreira da; OsóRIo, Paulo (2008): Introdução à história da língua portuguesa. Dos factores externos à dinâmica do sistema linguístico. Chamusca: Edições Cosmos. 